\title{
Selenium dioxide catalysed oxidation of acetic acid hydrazide by bromate in aqueous hydrochloric acid medium
}

\author{
R S YALGUDRE and G S GOKAVI* \\ Kinetics and Catalysis Laboratory, Department of Chemistry, Shivaji University Kolhapur 416 004, India \\ e-mail: gsgokavi@hotmail.com
}

MS received 8 June 2011; revised 31 August 2011; accepted 13 September 2011

\begin{abstract}
Selenium dioxide catalysed acetic acid hydrazide oxidation by bromate was studied in hydrochloric acid medium. The order in oxidant concentration, substrate and catalyst were found to be unity. Increasing hydrogen ion concentration increases the rate of the reaction due to protonation equilibria of the oxidant. The mechanism of the reaction involves prior complex formation between the catalyst and substrate, hydrazide, followed by its oxidation by diprotonated bromate in a slow step. Acetic acid was found to be the oxidation product. Other kinetic data like effect of solvent polarity and ionic strength on the reaction support the proposed mechanism.
\end{abstract}

Keywords. Acetic acid hydrazide; oxidation; bromate; kinetics; selenium dioxide; catalysis.

\section{Introduction}

Hydrazides of carbonic acids are important starting materials in organic synthesis ${ }^{1}$ as well as they find applications in medicine and analytical chemistry. ${ }^{2}$ They also form coordination complexes with many transition metal ions which make them good reagents for metal extraction, polymer stabilization and ion exchange problems. ${ }^{3-7}$ These hydrazides act as bidentate ligands involving carbonyl oxygen and the nitrogen $^{2}$ of the amino group of the hydrazine moiety with the metal ions. These hydrazides also exhibit carcinostatic, antibacterial and antifungal properties ${ }^{2}$ and complexation with metal ions is reported to enhance ${ }^{8}$ their biological activity. Selenium dioxide has been used as both oxidant and catalyst in various organic transformations. In organic synthesis it has been utilized as oxidant, ${ }^{9}$ dienophile agent, ${ }^{10}$ oxidative bond cleaving agent, ${ }^{11}$ as a catalyst for synthesis of urea derivatives, ${ }^{12}$ oxidative demethylating agent, ${ }^{13}$ benzylic oxidizing agent, ${ }^{14}$ allylic hydroxylating agent ${ }^{15}$ and in Beckmann rearrangement. ${ }^{16}$ Selenium dioxide has also been used as catalyst for oxidation of aldehydes ${ }^{16}$ in the presence of a secondary oxidant. Colloidal selenium has good photoelectrical properties which can be prepared by reducing selenium dioxide by hydrazine. Hydrazides are the derivatives of hydrazine ${ }^{17}$ therefore, interaction of these hydrazides with selenium dioxide in acidic solutions in the presence of an oxidant like bromate

*For correspondence offers an excellent opportunity to look into the mechanistic pathway.

The oxidative transformation of hydrazides, with most of the oxidants used, give corresponding acids and in some cases ${ }^{1}$ esters or amides. Hydrazides have also been converted into $\mathrm{N}-\mathrm{N}$-diacylhydrazines by various oxidants. ${ }^{18,19}$ Formation of acids and their derivatives in presence of different nucleophiles is the indication of direct two-electron transfer to the oxidant, ${ }^{20}$ while cyclization products generally involve a single electron transfer ${ }^{21}$ with intervention of a free radical. The oxidation of hydrazide by bromate in aqueous solutions does not occur and requires a catalyst. ${ }^{1}$ Potassium and sodium bromate are stable solids and easily handled as compared with liquid bromine and hypobromous acid solutions. The product of bromate oxidation is bromide ion which can be safely recycled thus making the methods of their oxidations environmentally benign than the metal ion oxidations. Bromates have been used for various organic oxidative transformations. ${ }^{22-26}$ Therefore, it is of significance to investigate the mechanism of oxidation of a hydrazide by bromate in the presence of selenium dioxide as a catalyst.

\section{Experimental}

The double distilled water was used throughout the work. All the chemicals used for experiments were of reagent grade. The stock solution of $\mathrm{KBrO}_{3}$ was prepared by dissolving $\mathrm{KBrO}_{3}(\mathrm{BDH})$ in water and standardized iodometrically. The solution of acetic acid 
hydrazide [acetohydrazide] (Spectrochem) was prepared by dissolving requisite amount of it in water.

The solution of catalyst selenium(IV) was obtained by dissolving selenium dioxide (SD fine) in distilled water. The ionic strength was maintained using sodium perchlorate and to vary hydrogen ion concentration $\mathrm{HCl}$ $(\mathrm{BDH})$ was used. Acetic acid and acrylonitrile were used directly as received to study the effect of solvent polarity on the reaction medium and free radical formation, respectively.

\subsection{Kinetic measurements}

The reaction was studied under pseudo-first-order conditions keeping hydrazide concentration in large excess over that of oxidant, $\mathrm{KBrO}_{3}$, at constant temperature of $27.0+0.1^{\circ} \mathrm{C}$. The reaction was initiated by mixing the previously thermostated solutions of the oxidant, catalyst and substrate, which also contained the required amount of hydrochloric acid, sodium perchlorate and distilled water. The reaction was followed by titrating $5 \mathrm{~cm}^{3}$ of the reaction mixture for unreacted oxidant iodometrically and the rate constants were determined from the pseudo-first-order plots of log[oxidant] against time. The pseudo-first-order plots were linear for more than $90 \%$ of the reaction and rate constants were reproducible within $+6 \%$.

\subsection{Stoichiometry and product analysis}

The stoichiometry of bromate oxidations predicts either $\mathrm{Br}_{2}$ or $\mathrm{HOBr}$ as the product of reaction but the hydrazides can be very easily oxidized by both of them in acidic solutions due to the oxidation potentials ${ }^{27}$ of $\mathrm{HOBr}$ and $\mathrm{Br}_{2}$ of 1.34 and $1.07 \mathrm{~V}$, respectively. The test for formation of bromide ion was carried out in sulphuric acid solution instead of hydrochloric acid by adding silver nitrate to the reaction mixture after completion of the reaction. The precipitation of silver bromide confirmed the formation of bromide ion as one of the product of the reaction. Therefore, the product of the reaction under the present experimental conditions is bromide ion. It is also noticed during the kinetic studies and the stoichiometric analysis that no bromine was evolved, confirming the bromide ion as the only product. The other product of the reaction is nitrogen gas and the effervescence of its evolution were observed during the kinetic runs as well as while determining the stoichiometry. The stoichiometry of the reaction was assessed by determining excess of bromate idometrically in presence of $1.0 \times 10^{-5} \mathrm{~mol} \mathrm{dm}^{-3} \mathrm{SeO}_{2}$ after completion of the reaction. It was found that three moles of hydrazide require two moles of bromate as shown in equation 1.

$$
\begin{aligned}
& 2 \mathrm{BrO}_{3}^{-}+3 \mathrm{CH}_{3} \mathrm{CONHNH}_{2} \\
& \quad \rightarrow 2 \mathrm{Br}^{-}+3 \mathrm{CH}_{3} \mathrm{COOH}+3 \mathrm{H}_{2} \mathrm{O}+3 \mathrm{~N}_{2} .
\end{aligned}
$$

\section{Results}

\subsection{Effect of oxidant and hydrazide concentration}

The uncatalysed reaction did not occur under the experimental conditions. The catalysed reaction was carried out under pseudo-first-order conditions keeping the concentration of hydrazide in large excess over the oxidant concentration at a constant concentrations of $\mathrm{HCl}$ and catalyst at $(0.1-1.0) \times 10^{-5} \mathrm{~mol} \mathrm{dm}^{-3}$, respectively at a constant ionic strength of $0.5 \mathrm{~mol} \mathrm{dm} \mathrm{dm}^{-3}$ (table 1). The pseudo-first-order plots were found to be linear on varying the concentration of oxidant between $2.0 \times 10^{-3}$ to $2.0 \times 10^{-2} \mathrm{~mol} \mathrm{dm}^{-3}$ keeping the concentration of catalyst and hydrazide constant at $1.0 \times$ $10^{-5}$ and $5.0 \times 10^{-2} \mathrm{~mol} \mathrm{dm}^{-3}$, respectively (table 1 )

Table 1. Effect of [bromate], [hydrazide] and $\left[\mathrm{H}^{+}\right]$on the selenium dioxide catalysed oxidation of acetic acid hydrazide by bromate at $\mathrm{T}=300 \mathrm{~K} \cdot 10^{5}[\mathrm{Se}(\mathrm{IV})]=$ $1.0 \mathrm{~mol} \mathrm{dm}^{-3}$ and $\mathrm{I}=0.5 \mathrm{~mol} \mathrm{dm}^{-3}$.

\begin{tabular}{lccc}
\hline $\begin{array}{l}10^{3}\left[\mathrm{BrO}_{3}^{-}\right] \\
\left(\mathrm{mol} \mathrm{dm}^{-3}\right)\end{array}$ & $\begin{array}{c}10^{2}[\text { hydrazide }] \\
\left(\mathrm{mol} \mathrm{dm}^{-3}\right)\end{array}$ & $\begin{array}{c}10\left[\mathrm{H}^{+}\right] \\
\left(\mathrm{mol} \mathrm{dm}^{-3}\right)\end{array}$ & $\begin{array}{c}10^{3} \mathrm{k}_{\text {obs }} \\
\left(\mathrm{s}^{-1}\right)\end{array}$ \\
\hline 2.0 & 5.0 & 1.0 & 0.62 \\
3.0 & 5.0 & 1.0 & 0.61 \\
4.0 & 5.0 & 1.0 & 0.61 \\
5.0 & 5.0 & 1.0 & 0.61 \\
6.0 & 5.0 & 1.0 & 0.62 \\
8.0 & 5.0 & 1.0 & 0.61 \\
10 & 5.0 & 1.0 & 0.62 \\
20 & 5.0 & 1.0 & 0.62 \\
5.0 & 1.0 & 1.0 & 0.62 \\
5.0 & 2.0 & 1.0 & 0.62 \\
5.0 & 3.0 & 1.0 & 0.62 \\
5.0 & 5.0 & 1.0 & 0.61 \\
5.0 & 8.0 & 1.0 & 0.62 \\
5.0 & 10 & 1.0 & 0.62 \\
5.0 & 5.0 & 0.5 & 0.15 \\
5.0 & 5.0 & 0.6 & 0.25 \\
5.0 & 5.0 & 0.8 & 0.32 \\
5.0 & 5.0 & 1.0 & 0.62 \\
5.0 & 5.0 & 1.5 & 1.4 \\
5.0 & 5.0 & 2.0 & 2.5 \\
5.0 & 5.0 & 2.5 & 4.0 \\
5.0 & 5.0 & 3.0 & 5.4 \\
5.0 & 5.0 & 3.5 & 6.8 \\
5.0 & 5.0 & 4.0 & 9.4 \\
\hline
\end{tabular}


indicating the order in oxidant concentration is unity. The pseudo-first-order rate constants, $\mathrm{k}_{\mathrm{obs}}$, were fairly constant as the concentration of hydrazide was varied between $1.0 \times 10^{-2}$ and $10.0 \times 10^{-2} \mathrm{~mol} \mathrm{dm}^{-3}$ keeping all other concentrations constant (table 1). Therefore, the order in hydrazide concentration is also unity.

\subsection{Effect of catalyst concentration}

The effect of catalyst concentration was studied in the concentration range of $2.0 \times 10^{-6}$ to $5.0 \times$ $10^{-5} \mathrm{~mol} \mathrm{dm}^{-3}$ and the plot of $\mathrm{k}_{\mathrm{obs}}$ against [catalyst] (figure 1) was found to be linear indicating the first order dependence of reaction on catalyst.

\subsection{Effect of hydrogen ion concentration}

The effect of hydrogen ion concentration was studied in order to understand the nature of reactant species present in the solution. The $\left[\mathrm{H}^{+}\right]$was varied between $5.0 \times 10^{-2}$ and $0.4 \mathrm{~mol} \mathrm{dm}^{-3}$ (table 1 ). Increasing $\left[\mathrm{H}^{+}\right]$ accelerates the rate of the reaction and the order in $\left[\mathrm{H}^{+}\right]$ is found to be 1.9 as determined from the plot of $\log \mathrm{k}_{\mathrm{obs}}$ against $\log \left[\mathrm{H}^{+}\right]$.

\subsection{Effect of ionic strength}

The effect of ionic strength was studied keeping [hydrazide], $\left[\mathrm{KBrO}_{3}\right]$, [catalyst] and $[\mathrm{HCl}]$ constant at $5.0 \times 10^{-2} \mathrm{~mol} \mathrm{dm}^{-3}, 5.0 \times 10^{-3} \mathrm{~mol} \mathrm{dm}^{-3}, 1.0 \times$ $10^{-5} \mathrm{~mol} \mathrm{dm}^{-3}$ and $0.1 \mathrm{~mol} \mathrm{dm}^{-3}$, respectively. Sodium perchlorate was used to vary the ionic strength. There was no effect of ionic strength on the reaction.

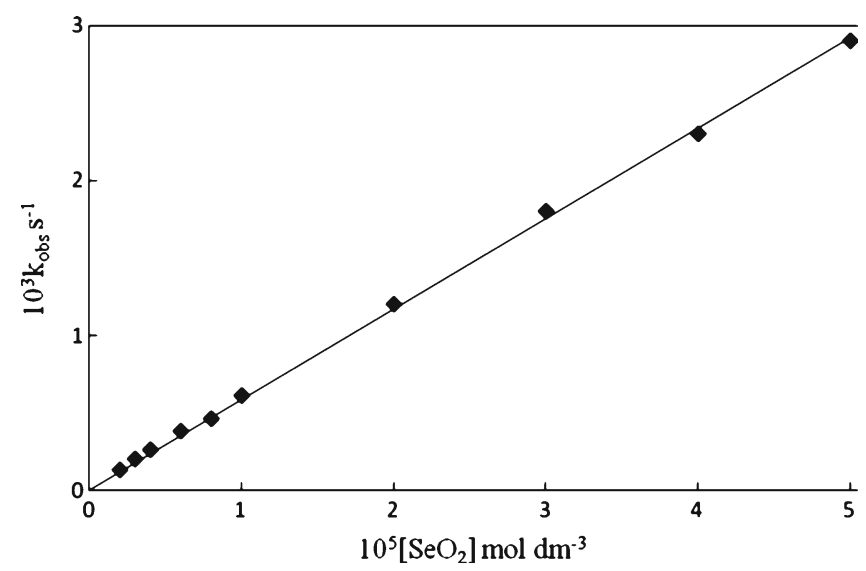

Figure 1. Effect of catalyst concentration on the selenium dioxide catalysed oxidation of acetic acid hydrazide by bromate at $\mathrm{T}=300 \mathrm{~K} \cdot 10^{3}\left[\mathrm{BrO}_{3}^{-}\right]=5.0 \mathrm{~mol} \mathrm{dm}{ }^{-3}$, $10^{2}[$ Hydrazide $]=5.0 \mathrm{~mol} \mathrm{dm}^{-3}$ and $\mathrm{I}=0.5 \mathrm{~mol} \mathrm{dm}^{-3}$.

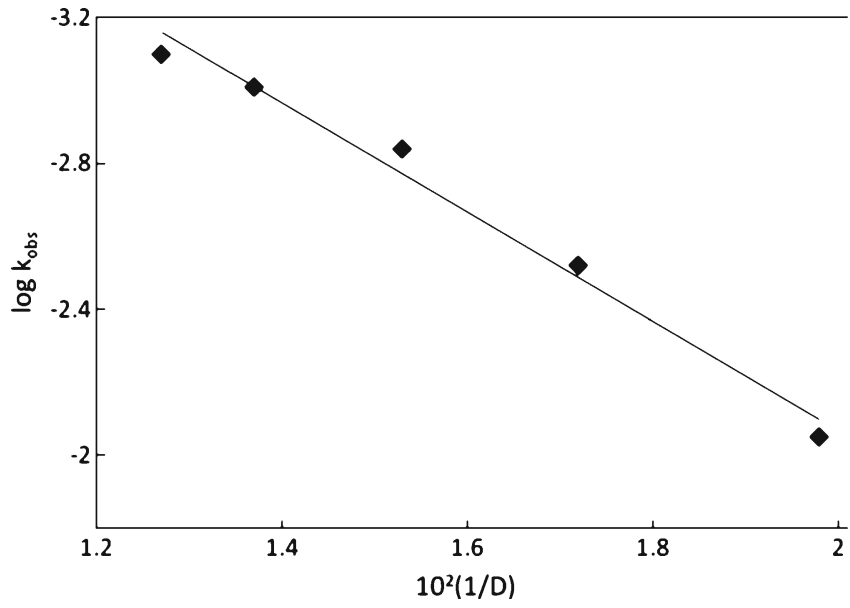

Figure 2. Plot of $\log \mathrm{k}_{\mathrm{obs}}$ against (1/D) at $\mathrm{T}=300 \mathrm{~K}$. $10^{3}\left[\mathrm{BrO}_{3}^{-}\right]=5.0 \mathrm{~mol} \mathrm{dm} \mathrm{dm}^{-3}, 10^{2}[$ Hydrazide $]=$ $5.0 \mathrm{~mol} \mathrm{dm}{ }^{-3},[\mathrm{HCl}]=0.1 \mathrm{~mol} \mathrm{dm} \mathrm{dm}^{-3} 10^{5}[\mathrm{Se}(\mathrm{IV})]=$ $1.0 \mathrm{~mol} \mathrm{dm}^{-3}$ and $\mathrm{I}=0.5 \mathrm{~mol} \mathrm{dm}^{-3}$.

\subsection{Test for free radical intervention}

In order to understand the intervention of free radicals in the reaction, the reaction was studied in the presence of added acrylonitrile. There was no induced polymerization of the acrylonitrile as there was no formation of the precipitate and also it did not affect the rate of the reaction.

\subsection{Effect of solvent polarity}

The effect of solvent polarity on the reaction was studied by varying percentage of acetic acid from 2 to $40 \% \mathrm{v} / \mathrm{v}$ keeping hydrazide and bromate concentration constant at $5.0 \times 10^{-2} \mathrm{~mol} \mathrm{dm}^{-3}, 5.0 \times$ $10^{-3} \mathrm{~mol} \mathrm{dm}^{-3}$, respectively and catalyst concentration at $1.0 \times 10^{-5} \mathrm{~mol} \mathrm{dm}^{-3}$. The dielectric constants of the reaction mixture were calculated by using the $\mathrm{D}$ values for pure solvents. It was found that the decrease in the dielectric constant of the medium increases the rate of the reaction. The plot of $\log \mathrm{k}_{\mathrm{obs}}$ against (1/D), where $\mathrm{D}$ is the dielectric constant, were found to be linear with negative slope as shown in figure 2 .

\section{Discussion}

The reaction was found to be accelerated by hydrogen ion concentration and the order in its concentration was found to be 1.9. Such acceleration due to the hydrogen ion concentration is either due to its direct involvement in any one of the steps of the mechanism or due to the existence of prior protonation equilibria. The oxidations by bromate in acidic medium are known ${ }^{28}$ to 
involve hydrogen ion dependent induction period due to initial slow oxidation of bromate by the reductant, as shown in equation (2), generating unreactive bromous acid, $\mathrm{HBrO}_{2}$. The bromous acid further undergoes disproportionation to generate reactive $\mathrm{HOBr}$ and

$$
\begin{aligned}
\mathrm{Red}+\mathrm{BrO}_{3}^{-}+3 \mathrm{H}^{+} & \rightarrow \mathrm{Ox}+\mathrm{HBrO}_{2}+\mathrm{H}_{2} \mathrm{O} \\
2 \mathrm{HBrO}_{2} & \rightarrow \mathrm{BrO}_{3}^{-}+\mathrm{HOBr}+\mathrm{H}^{+}
\end{aligned}
$$

bromate. Such induction periods were observed for the reductants with redox potential more than $1.1 \mathrm{~V}$. But in the present investigation there was no such induction period which was also not observed by Thompson. ${ }^{29}$ Therefore, the hydrogen ion dependence of the reaction is not due to the equilibrium (2) but due to one or more prior protonation equilibria. Selenium dioxide in aqueous solution exists as selenous acid, $\mathrm{H}_{2} \mathrm{SeO}_{3}$ and stepwise dissociations constants ${ }^{27}$ (Eq. 4 and 5) of this acid generating $\mathrm{HSeO}_{3}^{-}$and $\mathrm{SeO}_{3}^{2-}$

$$
\begin{aligned}
\mathrm{H}_{2} \mathrm{SeO}_{3} & \rightleftharpoons \mathrm{HSeO}_{3}^{-}+\mathrm{H}+ \\
\mathrm{HSeO}_{3}^{-} & \rightleftharpoons \mathrm{SeO}_{3}^{2-}+\mathrm{H}^{+}
\end{aligned}
$$

species are $2.4 \times 10^{-3} \mathrm{~mol} \mathrm{\textrm {dm } ^ { - 3 }}$ and $4.76 \times$ $10^{-9} \mathrm{~mol} \mathrm{dm}^{-3}$, respectively. The values of dissociation constants indicate that both the deprotonations occur in negligible extent in aqueous acidic solutions of the present study due to very low values of the disoociation constants. Therefore, under the present conditions of the reaction, selenium dioxide exists as selenous acid which is the active species of the catalyst. Another possible protonation in the present system would be that of the hydrazides. Hydrazides are known to undergo protonation ${ }^{30}$ and the $\mathrm{pK}$ of the acetic acid hydrazide is reported ${ }^{31}$ to be 3.24 . Using the reported $\mathrm{pK}$ of acetic acid hydrazide the concentration of the protonated hydrazide was calculated. It was found that as under the hydrogen ion concentration of the present study, hydrazide is completely converted into its protonated (Eq. 6) form indicating protonated hydrazide as the

$$
\mathrm{CH}_{3} \mathrm{CONHNH}_{3}^{+} \rightleftharpoons \mathrm{CH}_{3} \mathrm{CONHNH}_{2}+\mathrm{H}^{+}
$$

active species of the reductant. Potassium bromate is a strong electrolyte and in aqueous solution it exists as $\mathrm{BrO}_{3}^{-}$. In a recent study, protonation of $\mathrm{BrO}_{3}^{-}$has been considered ${ }^{32,33}$ in presence of strong acids generating diprotonated $\mathrm{H}_{2} \mathrm{BrO}_{3}^{+}$with a reported protonation constant ${ }^{32}$ of $0.21 \mathrm{dm}^{6} \mathrm{~mol}^{-2}$. The order of about 1.9 in hydrogen ion concentration can be explained by considering the diprotonated bromate, $\mathrm{H}_{2} \mathrm{BrO}_{3}^{+}$as the active species of the oxidant. The mechanism of the reaction considering $\mathrm{H}_{2} \mathrm{SeO}_{3}, \mathrm{H}_{2} \mathrm{BrO}_{3}^{+}$and protonated acetic acid hydrazide as the active species of the catalyst, oxidant and substrate, respectively is shown in scheme 1 . The mechanism of scheme 1 involves formation of a complex between catalyst, $\mathrm{H}_{2} \mathrm{SeO}_{3}$, and protonated hydrazide in a fast prior equilibrium. The complex thus formed is then oxidized by active diprotonated oxidant, $\mathrm{H}_{2} \mathrm{BrO}_{3}^{+}$, in a rate determining step generating catalyst along with $\mathrm{HBrO}_{2}$ and acyl diimide as the intermediates of the oxidant and the substrate, respectively.

Hydrazides are good reductants with reduction potential of benzoic acid hydrazide ${ }^{34}$ is reported to be $0.19 \mathrm{~V}$. Preliminary experiments in the absence of bromate have indicated that red colloidal selenium was precipitated which on standing turns grey. But in the presence of oxidant no such precipitation was observed and the pseudo-first-order plots were linear for all the kinetic runs. If the catalyst is reduced completely to selenium metal, which is oxidized by bromate rapidly in acidic medium, then the reaction would have been independent of bromate concentration resulting in zero-order kinetics. Further, bromate has been used $^{35}$ as an analytical volumetric reagent for the titration of small amount of colloidal selenium. In such titration the colloidal selenium is oxidized to selenous acid and further oxidation to selenic acid by bromate does not takes place. Therefore, considering the kinetic data obtained and the reported results, the mechanism of the reaction involves fast complex formation between the catalyst and hydrazide in a prior equilibria followed by its oxidation by the diprotonated bromate as shown in scheme 1 . According to the mechanism summarized in scheme 1, the corresponding rate law can be represented as in equation (7) corresponding expression for the $\mathrm{k}_{\mathrm{obs}}$ as in equation (8).

$$
\begin{aligned}
\text { Rate }= & \mathrm{k}_{1} \mathrm{~K}_{1} \mathrm{~K}_{2} \mathrm{~K}_{3}\left[\mathrm{H}^{+}\right]^{2} \\
& \times\left[\mathrm{H}_{2} \mathrm{SeO}_{3}\right]\left[\mathrm{CH}_{3} \mathrm{CONHNH}_{2}\right] \\
& \times\left[\mathrm{BrO}_{3}\right] /\left(1+\mathrm{K}_{1}\left[\mathrm{H}^{+}\right] \mathrm{K}_{1} \mathrm{~K}_{2}\left[\mathrm{H}^{+}\right]^{2}\right) \\
\mathrm{k}_{\mathrm{obs}}= & \mathrm{k}_{1} \\
& \mathrm{~K}_{1} \mathrm{~K}_{2} \mathrm{~K}_{3}\left[\mathrm{H}^{+}\right]^{2} \\
& \times\left[\mathrm{H}_{2} \mathrm{SeO}_{3}\right] /\left(1+\mathrm{K}_{1}\left[\mathrm{H}^{+}\right]+\mathrm{K}_{1} \mathrm{~K}_{2}\left[\mathrm{H}^{+}\right]^{2}\right) .
\end{aligned}
$$

The $\mathrm{pK}$ of protonation of bromate in aqueous acidic solutions have been reported ${ }^{33}$ to be in the range of -0.5 to 2.3 on the basis of kinetic results. The equilibrium constant of equation (9) of scheme 1 is $3.16 \mathrm{dm}^{3} \mathrm{~mol}^{-1}$ and the cumulative equilibrium constants $\mathrm{K}_{1}$ and $\mathrm{K}_{2}$ is reported ${ }^{32}$ to be $0.21 \mathrm{dm}^{6} \mathrm{~mol}^{-2}$. 


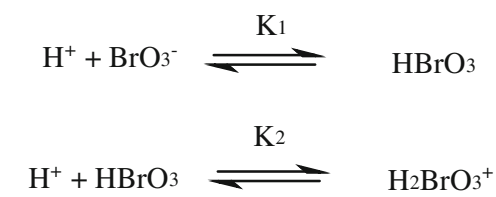

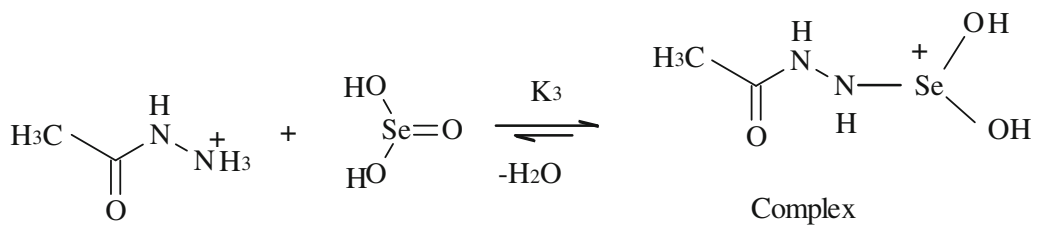

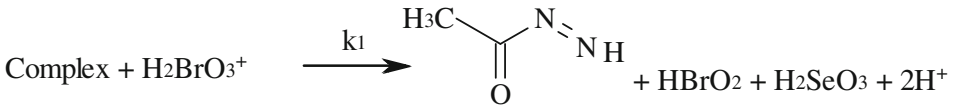

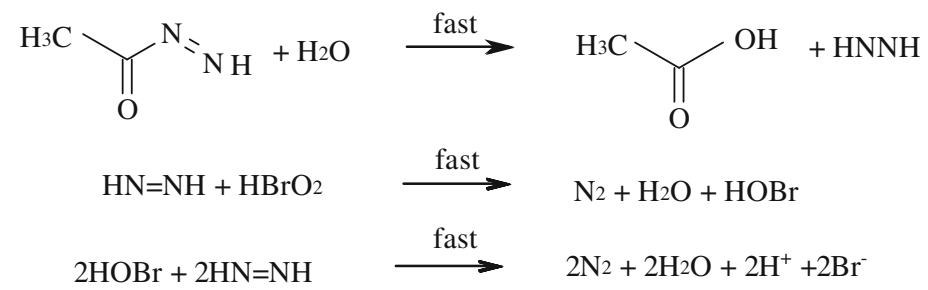

Scheme 1. Detailed mechanism of selenium dioxide catalysed oxidation of acetic acid hydrazide by bromate.

From these values, the equilibrium constant of equation (10) of scheme 1 can be calculated as $6.6 \times$ $10^{-2} \mathrm{dm}^{3} \mathrm{~mol}^{-1}$. It was also found that the denominator of equation (8) does not vary to a considerable extent within the range of the hydrogen ion concentration studied when the values of $K_{1}$ and $K_{2}$ are substituted. Therefore, if we neglect the contribution from the denominator in comparison with 1 the expression (8) simplifies to equation (16). The plot of $\mathrm{k}_{\mathrm{obs}}$ against $\left[\mathrm{H}^{+}\right]^{2}$ is found to be linear $\left(\mathrm{R}^{2}=0.9967\right)$ thus verifying the proposed mechanism and the rate law.

$$
\mathrm{k}_{\mathrm{obs}}=\mathrm{k}_{1} \mathrm{~K}_{1} \mathrm{~K}_{2} \mathrm{~K}_{3}\left[\mathrm{H}^{+}\right]^{2}\left[\mathrm{H}_{2} \mathrm{SeO}_{3}\right] .
$$

The derived expression (16) for the pseudo-firstorder rate constant based on the mechanism of scheme 1 explains the order of two in $\left[\mathrm{H}^{+}\right]$and an order of unity in the [catalyst]. The reaction is also not affected by the change in the ionic strength indicating one of the species involved in the prior equilibria (Eq. 11, scheme 1) of the reaction would be $\mathrm{H}_{2} \mathrm{SeO}_{3}$. The formation diimide intermediates have been proposed during oxidative conversion of hydrazine moiety by various oxidizing reagents. ${ }^{1,18}$ Since the reaction did not follow the Michealis-Menten type of catalysis the formation of the complex between the catalyst and hydrazide as shown is fast (scheme 1). The test for free radicals was found to be negative therefore, the reaction proceeds without any intervention of free radicals. This observation was also supported by the product analysis in which corresponding acetic acid was the only product obtained. The $\mathrm{N}-\mathrm{N}$-diacylhydrazine would have been obtained along with acetic acid as a result of free radical intervention in the reaction. Colloidal selenium was not formed in any of the kinetic runs although it has been obtained in the absence of oxidant. Therefore, it was assumed that the complex formed between catalyst and hydrazide is oxidized by bromate in a rate determining step.

Further, the nucleophilic attack of water molecule on the carbonyl carbon of acyl diimide intermediate give acetic acid and another intermediate $\mathrm{NH}=\mathrm{NH}$ as shown in scheme 1 . The fast oxidation of $\mathrm{NH}=\mathrm{NH}$ by the $\mathrm{HOBr}$ will complete the observed stoichiometry of the reaction. The final product of bromate reduction in the present study is considered to be bromide ion rather than bromine which can be justified by its thermodynamic feasibility predicted from the known redox potentials in the following manner. In scheme 1, $\mathrm{HOBr}$ is proposed as the bromate intermediate generated as a result of its reduction. The redox potentials of the couples $2 \mathrm{HOBr} / \mathrm{Br}_{2}$ and $\mathrm{HOBr} / \mathrm{Br}^{-}$are $1.6 \mathrm{~V}$ and 
$1.34 \mathrm{~V}$, respectively. The conversion of $\mathrm{HOBr}$ into $\mathrm{Br}_{2}$ is thermodynamically more favourable than into $\mathrm{Br}^{-}$. But the generation of bromine requires two moles of $\mathrm{HOBr}$ whose concentration is very small in the reaction mixture. Further, the rate constant of direct oxidation of bromide in acidic solutions by bromate ${ }^{36}$ is $3.94 \times 10^{-3} \mathrm{dm}^{3} \mathrm{~mol}^{-1} \mathrm{~s}^{-1}$ indicating its slowness and requires excess of $\left[\mathrm{Br}^{-}\right]$. Therefore, in the proposed mechanism (scheme 1) $\mathrm{Br}^{-}$is considered as the product rather than $\mathrm{Br}_{2}$. The decrease in relative permittivity of the reaction medium with increase in acetic acid content increases the rate of reaction and the plot of $\log$ $\mathrm{k}_{\mathrm{obs}}$ against (1/D), where $\mathrm{D}$ is the dielectric constant of the medium, is linear (figure 2) with a negative slope. The charge separation in the transition state formed and its larger size increases its stability ${ }^{37}$ in the medium of higher relative permittivity thus, increasing the rate of reaction with increase in acetic acid content.

\section{Conclusions}

The reaction between $\mathrm{KBrO}_{3}$ and acetic acid hydrazide in the presence of selenium(IV) as a catalyst occurs through formation of a complex between catalyst and hydrazide which will be oxidized by the oxidant in a rate determining step. The mechanism proposed on the basis of kinetic data does not involve any free radical intervention and corresponding acetic acid as the product. The active species in the present study are the protonated forms of the hydrazide and $\mathrm{H}_{2} \mathrm{SeO}_{3}$ of catalyst. The dependence of rate of reaction on hydrogen ion concentration of the order of two is due to the successive protonation of bromate to $\mathrm{H}_{2} \mathrm{BrO}_{3}^{+}$species.

\section{Acknowledgement}

One of the authors RSY acknowledges the University Grants Commission (UGC), New Delhi for the award of Teacher Fellowship under FIP- UGC-XI plan.

\section{References}

1. Kocevar M, Mihorko P and Polanc S 1995 J. Org. Chem. 601466

2. Gudasi K B, Patil M S, Vadavi R S, Shenoy R V, Patil S A, and Nethaji M 2007 Spectrochim Acta. Part A 67 172

3. Zubareva G I, Adeev S U, Radushev A V, Gomzikov A I and Zubarev M P 1998 Z. Prikladnoi Khimii 71(2) 271

4. Shen X and Giese R W 1997 J. Chromatogr. A 777261
5. Lunn G, Philips L R and Pacula-Cox C 1998 J. Chromatogr. B $\mathbf{7 0 8} 217$

6. Gad A M, El-Dissouky A, Mansour E M and El-Maghraby A 2000 Polym. Degrad. Stab. 68153

7. Gursoy A, Terzioglu N and Otuk G 1997 Eur. J. Med. Chem. 32753

8. Singh B, Shrivastava R and Narang K K 2000 Synth. React. Inorg. Met. Org. Chem. 301175

9. Priewisch B and Ruck-Brown K 2005 J. Org. Chem. 70 2350

10. Nguyen T M, Guzei I A and Lee D 2002 J. Org. Chem. 676553

11. Kariyone K and Yazawa H 1970 Tetrahedron Lett. 11 2885

12. Chen J, Ling G and Lu S 2003 Tetrahedron 598251

13. Goswami S P and Maity A C 2007 Chem. Lett. 361118

14. Goswami S P and Adak A K 2003 Synth. Commun. 33 475

15. Madec D and Ferezou J P 1996 Synlett. 867

16. Sosnovsky G and Krogh J A 1978 Synthesis 703

17. Gates B, Yin Y and Xia Y 2000 J. Am. Chem. Soc. 122 12582

18. Kulkarni P P, Kadam A J, Desai U V, Mane R B and Wadgaonkar P P 2000 J. Chem. Res. (S) 184

19. Jadhav V K, Wadgaonkar P P and Salunkhe M M 1998 J. Chin. Chem. Soc. 45831

20. Kadam S D, Supale A R and Gokavi G S 2008 Z. Phys. Chem. 222635

21. Shewale S A, Phadkule A N and Gokavi G S 2008 Int. J. Chem. Kinetics 40151

22. Farkas L, Perlmutter B and Schachter O 1949 J. Am. Chem. Soc. 712833

23. Farkas L and Schachter O 1949 J. Am. Chem. Soc. 71 2827

24. Mirjalili B F, Zolfigol M A, Bamoniri A, Zaghaghi Z and Hazar A 2003 Acta Chim. Slov. 50563

25. Tomioka H, Oshima K and Nozaki H 1982 Tetrahedron Lett. 23539

26. Yamamoto Y, Suzuki H and Moro-oka Y 1985 Tetrahedron Lett. 262107

27. Lurie Ju 1971 Handbook of analytical chemistry (Moscow: MIR Publishers)

28. Mohammad A 2003 Transition Met. Chem. 28345

29. Thomson R C 1971 Inorg. Chem. 101892

30. Manoussakis G, Haristos D and Youri C 1973 Can. J. Chem. 51811

31. Lindegren R and Niemann C 1949 J. Am. Chem. Soc. 71 1504

32. Reddy C S and Manjari P S 2010 Indian J. Chem. 49A 418

33. Cortes C E S and Faria R B 2001 J. Braz. Chem. Soc. 12 775

34. Amos R I J, Gourlay B S, Schiesser C H, Smith J A and Yates B F 2008 Chem. Commun. 1695

35. Coleman W C and McCrosky C R 1937 Ind. Eng. Chem, Anal. Ed 91458

36. Domínguez A and Iglesias E 1998 Langmuir 142677

37. Amis E S 1966 Solvent effects on the reaction and mechanism (New York: Academic Press) 